\section{Time to Re-Evaluate Clozapine Practices}

Received: November 13, 2016; Accepted: November 14, 2016; Published: November 20, 2016

\section{Editorial}

Duration of Untreated Psychosis (DUP) is defined as the time from manifestation of the first psychotic symptom to the initiation of adequate antipsychotic drug treatment. It is well established that longer duration in the first episode of psychosis is associated with poorer treatment response and outcomes [1]. The early psychosis intervention movement therefore adopts various strategies to reduce the DUP, and provides intensive multidisciplinary care in the early stages of the illness in hopes of improving outcomes and changing the trajectory of the disease [2].

\section{Treatment Resistance in First Episode Psychosis}

Despite best efforts, symptomatic non-remission or treatment resistance is still fairly common in patients with First Episode Psychosis (FEP); with short term follow up studies reporting ranges between $17 \%$ and $25 \%$ in Western populations [3-9]. When Simonsen et al. [10] set out to identify predictors of nonremission in 301 Scandinavian patients with FEP, they found that $43 \%$ of patients remained psychotic at 3 months, and $16.4 \%$ of patients continued to remain psychotic over 2 years, based on a priori defined Positive and Negative Syndrome Scale (PANSS) [11] cut-off scores. A long DUP predicted both 3-month and 2-year non-remission rates; whereas early treatment response was shown to correlate with better outcomes [10].

Correspondingly, in a study conducted in 2012 examining the rates of symptomatic and functional remission in a cohort of patients with FEP on follow up with the Singapore Early Psychosis Intervention Programme (EPIP), only $54.1 \%$ of patients achieved symptomatic remission; $58.4 \%$ achieved functional remission; and $29.4 \%$ achieved both symptomatic and functional remission at 2 years [12]. Symptomatic remission was defined based on the criteria proposed by the Schizophrenia Working Group [13], that is, achieving and maintaining a PANSS rating of 3 or less for a duration of at least 6 months on the following items: Delusions (P1), unusual thought contents (G9), hallucinatory behaviour (P3), conceptual disorganization (P2), mannerisms (G5), blunted affect (N1), social withdrawal (N4) and lack of spontaneity (N6). Functional remission was defined as a Global Assessment of Functioning (GAF) [14] disability score of $\geq 61$ with engagement in age-appropriate vocation. Patients who fulfilled the criteria for both symptomatic and functional remission were considered to be in recovery. In addition, at 3 months, only $45.6 \%$ of patients

\section{Charmaine Tang Yu Zheng}

\author{
Department of Early Psychosis \\ Intervention, Institute of Mental Health, \\ Singapore
}

\author{
Corresponding author: \\ Charmaine Tang Yu Zheng \\ charmaine_yz_tang@imh.com.sg
}

Associate Consultant, Department of Early Psychosis Intervention, Institute of Mental Health, 10 Buangkok View, Singapore 539747, Singapore.

Tel: (65) 63892000
Fax: (65) 63851050

Citation: Yu Zheng CT. Time to Re-Evaluate Clozapine Practices. Acta Psychopathol. 2016, 2:6.

had a minimum $40 \%$ improvement in PANSS from baseline, and were classified as early responders [15]. Using multiple logistic regressions, the authors were able to show that shorter DUP and early response were significant predictors of recovery [12].

Although there have not been any studies directly examining the rates and predictors of symptomatic non-remission or treatment resistance in patients with FEP in an Asian population, it is reasonable to deduce, based on current literature, that reducing DUP and achieving early symptomatic response are perhaps the most crucial modifiable factors in preventing treatment resistance and improving long term outcomes. Hence, it will be wise for early intervention programmes to dedicate time and resources to examining and implementing strategies to not only reducing DUP, but also to achieving early symptomatic response.

\section{Effectiveness of Clozapine in Symptom Reduction}

Clozapine is generally considered to be the most effective antipsychotic medication. It has unique efficacy for Treatment Resistant Schizophrenia (TRS) [16], and there is evidence for its superiority to other typical and atypical antipsychotics for nontreatment resistant schizophrenia as well. 
The Phase 2 Clinical Antipsychotic Trials for Interventions Effectiveness (CATIE) study [17] compared the effectiveness of clozapine (as second-line treatment) to the newer atypical antipsychotics (specifically olanzapine, quetiapine, and risperidone) in a population of patients with schizophrenia who did not respond to a prior atypical antipsychotic treatment. Treatment with clozapine was shown to be significantly more effective than switching to another of the newer atypical antipsychotics. Time until treatment discontinuation for any reason was longer for clozapine (median=10.5 months) than for quetiapine (median=3.3 months), risperidone (median=2.8 months) or olanzapine (median=2.7 months). In particular, patients receiving clozapine were less likely to discontinue treatment because of inadequate therapeutic response than were patients receiving any of the newer atypical antipsychotics. Of note, results were strong enough to achieve statistical significance despite small groups $(n=99)$.

Studies examining the role of clozapine as first-line treatment in schizophrenia are limited, but have also shown promising results. In a 52-week randomized double-blind controlled trial comparing clozapine and chlorpromazine in 160 treatment naïve patients experiencing their first episode of schizophrenia, Lieberman et al. [18] reported that treatment with clozapine led to greater efficacy after 12 weeks of in-patient treatment; faster time to remission (50\% of patients with clozapine had remitted in 8 weeks compared to 12 weeks in patients with chlorpromazine); and greater time spent in remission (patients assigned to clozapine remained in remission almost twice the time of those assigned to chlorpromazine). Although these efficacy differences were no longer observed by 52 weeks, the authors postulated that the failure to sustain significant differences in symptom reduction beyond 12 weeks could have been due to more posthospitalization dropouts among less responsive patients in the chlorpromazine group, thereby decreasing the differences in improvement seen at 52 weeks. When this cohort of patients were followed up for an additional 7 years of naturalistic treatment, the findings supported the comparability of effectiveness between chlorpromazine and clozapine, but showed that the clozapine group was more likely to remain on the medication to which they were originally assigned ( $26 \%$ vs. $10 \%, p=0.01)$, suggesting greater tolerability of clozapine in the treatment of FEP [19].

In an observational study, Agid et al. [20] implemented a standardized treatment algorithm in their First Episode Psychosis Program, with patients receiving 2 trials of 2 different atypical antipsychotics (olanzapine, quetiapine, or risperidone), followed by a trial of clozapine as early as 25 weeks into the start of their treatment. Comparing the clozapine-treated group and the group who refused clozapine and chose to continue the same antipsychotic treatment as before, patients who received clozapine had significant improvements in their Brief Psychiatric Rating Scale (BPRS) [21] and Clinical Global Impression - Severity scale (CGI-S) [22] scores. Subjects who received clozapine experienced a mean BPRS score change of 19 points (from 53.5 to 34.5 ) and a change in the mean CGI-S scale rating from 5.4 to 3.5 (i.e., from severely ill to mildly ill); those who refused clozapine had a 2-point increase in mean BPRS score (from 53 to 55) and a 0.6-point increase in the mean CGI-S rating from
5.4 to 6 (i.e., remaining markedly to severely ill). The authors showed that in FEP, an early switch to clozapine was superior to extending an antipsychotic trial in hopes of achieving response. They therefore suggest that clozapine has a very important role in the early treatment of first episode patients whose psychosis does not remit with other atypical antipsychotics during the first few months of treatment [20].

\section{Other Benefits of Clozapine}

Beyond benefits in symptom reduction, several robust large scale studies have shown that clozapine use is associated with cognitive improvements [23-26]; increased treatment compliance [27]; substantially lower mortality [28]; and significant reduction in suicidal behaviour [29-31].

In a multicentre, randomized, international, 2-year study conducted by the International Suicide Prevention Trial (InterSePT) study group [30], the authors found that suicidal behaviour was significantly less in patients treated with clozapine than with olanzapine. Fewer clozapine-treated patients attempted suicide, required hospitalizations or rescue interventions, or required concomitant treatment with antidepressants, anxiolytics or soporifics. The anti-suicidal effect of clozapine was further substantiated in an 11-year follow up study conducted by Tiihonen et al. [28]. In this population-based cohort study, nationwide registers in Finland were used to compare the causespecific mortality in 66881 patients with schizophrenia versus the total population (5.2 million), and to link these data with the use of antipsychotic drugs. The authors showed that long term cumulative exposure to any antipsychotic treatment was associated with lower mortality than was no drug use. More significantly, clozapine was associated with a substantially lower all-cause mortality and suicide-specific mortality than any other antipsychotic (including perphenazine, thioridazine, haloperidol, risperidone, olanzapine and quetiapine), prompting the authors to question if restrictions on clozapine use should be reassessed.

In terms of costs, Duggan et al. [32] stressed the cost-effectiveness of clozapine, estimating that its correct and early use will mean a savings of 8.7 million pounds and 53 deaths per year in the United Kingdom. For Wang et al. [33], the use of clozapine as first choice treatment in FEP can lead to an improvement in the quality of life and life expectancy in this group of patients. They also suggested that the cost-effectiveness is comparable to that accepted for many medical interventions.

\section{Delay in Clozapine Initiation}

In our clinical setting, the use of clozapine is considered only in treatment resistant patients who have failed at least 2 adequate trials of different antipsychotics, of which one must be a nonclozapine atypical antipsychotic. In addition, there is often a hesitancy to start clozapine given its side effect profile, need for regular haematological monitoring, and perceived position as treatment of "last resort". Avoidance of clozapine initiation is rife, despite current clinical guidelines, for example the National Institute for Health and Clinical Excellence (NICE) guidelines for psychosis and schizophrenia [34], advocating otherwise. This is most recently evidenced by the report from the second round of 
the National Audit of Schizophrenia (NAS2) [35], which highlighted that patients whose illness was poorly responsive to standard antipsychotic medications were waiting too long to be started on clozapine. The authors found that $28 \%$ of patients whose illness was not in remission, and who were probably appropriate for a trial of clozapine, had not yet been commenced on clozapine; $57 \%$ of patients receiving clozapine had been prescribed 3 or more antipsychotic medications prior to commencing clozapine, which meant that their progress, to a medication more likely to be effective for them, had been delayed.

\section{Time to Re-Evaluate Clozapine Practices}

Overall, studies and expert opinions suggest that negative attitudes to clozapine and perhaps even restrictions on the use of clozapine should be reassessed considering the risk-benefit ratio. Given the clear therapeutic advantages of clozapine in TRS, clinicians should strive to minimize inappropriate delays to clozapine initiation by reviewing and understanding their prescription practices, and eradicating obstacles that contribute to clozapine's underuse.

As described in the above paragraphs, several studies have also made compelling arguments for the repositioning of clozapine as second-line or even first-line treatment. The benefits of clozapine in terms of symptom reduction, cognitive improvements, reduced mortality, and cost-effectiveness suggest that an early switch to clozapine may be superior to switching to another non-clozapine antipsychotic, or extending an antipsychotic trial in hopes of achieving response.

This is particularly relevant to patients with FEP, given that the initial interventions in treatment naïve patients present a critical therapeutic opportunity that has the potential to improve rates of early symptomatic response and reduce the duration spent in FEP, thereby influencing the course and outcome of what could be a lifelong illness. 


\section{References}

1 Marshall M, Lewis S, Lockwood A, Drake R, Jones P, et al. (2005) Association between duration of untreated psychosis and outcome in cohorts of first-episode patients: a systematic review. Arch Gen Psychiat 62: 975-983.

2 Bertolote J, McGorry P (2005) Early intervention and recovery for young people with early psychosis: consensus statement. $\mathrm{Br} \mathrm{J}$ Psychiat 187: s116-119.

3 Addington J, Addington D (2008) Symptomatic remission in first episode patients. Schizophr Res 106: 281-285.

4 Huber CG, Naber D, Lambert M (2008) Incomplete remission and treatment resistance in first-episode psychosis: definition, prevalence and predictors. Expert Opin Pharmacother 9: 2027-2038.

5 Lambert M, Conus P, Schimmelmann BG, Eide P, Ward J, et al. (2005) Comparison of olanzapine and risperidone in 367 first-episode patients with non-affective or affective psychosis: results of an open retrospective medical record study. Pharmacopsychiatry 38: 206213.

6 Lambert M, Naber D, Schacht A, Wagner T, Hundemer HP, et al. (2008) Rates and predictors of remission and recovery during 3 years in 392 never-treated patients with schizophrenia. Acta Psychiatr Scand 118: 220-229.

7 Malla A, Norman R, Bechard-Evans L, Schmitz N, Manchanda R, et al. (2008) Factors influencing relapse during a 2-year follow-up of firstepisode psychosis in a specialized early intervention service. Psychol Med 38: 1585-1593.

8 Manchanda R, Norman RM, Malla AK, Harricharan R, Northcott S (2005) Persistent psychoses in first episode patients. Schizophr Res 80: 113-116.

9 Menezes NM, Malla AM, Norman RM, Archie S, Roy P, et al. (2009) A multi-site Canadian perspective: examining the functional outcome from first-episode psychosis. Acta Psychiatr Scand 120: 138-146.

10 Simonsen E, Friis S, Opjordsmoen S, Mortensen EL, Haahr U, et al. (2010) Early identification of non-remission in first-episode psychosis in a two-year outcome study. Acta Psychiatr Scand 122: 375-383.

11 Kay SR, Fiszbein A, Opler LA (1987) The positive and negative syndrome scale (PANSS) for schizophrenia. Schizophr Bull 13: 261276.

12 Verma S, Subramaniam M, Abdin E, Poon LY, Chong SA (2012) Symptomatic and functional remission in patients with first-episode psychosis. Acta Psychiatr Scand 126: 282-289.

13 Andreasen NC, Carpenter WT, Kane JM, Lasser RA, Marder SR, et al. (2005) Remission in schizophrenia: proposed criteria and rationale for consensus. Am J Psychiat 162: 441-449.

14 Frances A, Pincus HA, First MB (1994) The global assessment of functioning scale (GAF) in Diagnostic and Statistical Manual of Mental Disorder-IV. Washington, DC: American Psychiatric Association.

15 Kinon BJ, Chen L, Ascher-Svanum H, Stauffer VL, Kollack-Walker S, et al. (2008) Predicting response to atypical antipsychotics based on early response in the treatment of schizophrenia. Schizophr Res 102 230-340.

16 Kane JM, Honigfeld G, Singer J, Meltzer H (1988) Clozapine for the treatment-resistant schizophrenic: a double-blind comparison with chlorpromazine. Arch Gen Psychiatry 45: 789-796.

17 McEvoy JP, Lieberman JA, Stroup TS, Davis SM, Meltzer HY, et al.
(2006) Effectiveness of clozapine versus olanzapine, quetiapine, and risperidone in patients with chronic schizophrenia who did not respond to prior atypical antipsychotic treatment. Am J Psychiat 163: 600-610.

18 Lieberman JA, Phillips M, Gu HB, Stroup S, Zhang P, et al. (2003) Atypical and conventional antipsychotic drugs in treatment-naïve first-episode schizophrenia: a 52-week randomized trial of clozapine vs. chlorpromazine. Neuropsychopharmacology 28: 995-1003.

19 Girgis RR, Phillips MR, Li X, Li K, Jiang H, et al. (2011) Clozapine v. chlorpromazine in treatment-naïve, first-episode schizophrenia: 9-year outcomes of a randomised clinical trial. Br J Psychiat 199: 281-288.

20 Agid O, Remington G, Kapur S, Arenovich T, Zipursky RB (2007) Early use of clozapine for poorly responding first-episode psychosis. J Clin Psychopharmacol 27: 369-373.

21 Overall JEG (1962) The brief psychiatric rating scale. Psychol Rep 10: 799-812.

22 Guy W (1976) Clinical global impression. Rockville, MD: U.S Department of Health, Education, and Welfare, Public Health Service, Alcohol, Drug Abuse, and Mental Health Administration, NIMH Psychopharmacology Research Branch, Division of Extramural Research Programs.

23 Asenjo LC, Komossa K, Rummel-Kluge C, Hunger H, Schmid F, et al. (2010) Clozapine versus other atypical antipsychotics for schizophrenia. Cochrane Database Syst Rev 10: CD006633.

24 McGurk SR (1999) The effects of clozapine on cognitive functioning in schizophrenia. J Clin Psychiat 60: 24-29.

25 Manschreck TC, Redmond DA, Candela SF (1999) Effects of clozapine on psychiatric symptoms, cognition and functional outcome in schizophrenia. J Neuropsychiat Clin Neurosci 11: 481-489.

26 Hagger C, Buckley P, Kenny JT, Friedman L, Ubogy D, et al. (1993) Improvement in cognitive functions and psychiatric symptoms in treatment-refractory schizophrenic patients receiving clozapine. Biol Psychiat 34: 702-712.

27 Tiihonen J, Wahlbeck K, Lonnqvist J, Klaukka T, loannidis JPA, et al. (2006) Effectiveness of antipsychotic treatments in a nationwide cohort of patients in community care after first hospitalization due to schizophrenia and schizoaffective disorder: observational followup study. BMJ 333: 224-227.

28 Tiihonen J, Lonnqvist J, Wahlbeck K, Klaukka T, Niskanen L, et al. (2009) 1 year follow-up of mortality in patients with schizophrenia: a population-based cohort study (FIN11 study). Lancet 374: 620-627.

29 Meltzer HY (2005) Suicide in schizophrenia, clozapine and adoption of evidence-based medicine. J Clin Psychiat 66: 530-533.

30 Meltzer HY, Alphs L, Green AL, Anand R, Bertoldi A, et al. (2003) Clozapine treatment for suicidality in schizophrenia: International Suicide Prevention Trial (InterSePT). Arch Gen Psychiat 60: 82-91.

31 Hennen J, Baldessarini RJ (2005) Suicide risk during treatment with clozapine: a meta-analysis. Schizophr Res 73: 139-145.

32 Duggan A, Warner J, Knapp M, Kerwin R (2003) Modelling the impact of clozapine on suicide in patients with treatment resistant schizophrenia in the UK. Br J Psychiatry 182: 505-508.

33 Wang PS, Ganz DA, Benner JS, Glynn RJ, Avorn J (2004) Should clozapine continue to be restricted to third-line status for schizophrenia?: a decision-analytic model. J Ment Health Policy Econ 7: $77-85$ 
34 National Institute for Health and Clinical Excellence (NICE) (2014) Psychosis and schizophrenia in adults: treatment and management. London: NICE, February.
35 Royal College of Psychiatrists (2014) Report of the second round of the national audit of schizophrenia (NAS) 2014. London: Healthcare Quality Improvement Partnership. 